\title{
Determination of the Risk Factors Impact on the Construction Projects Implementation Using Fuzzy Sets Theory
}

\author{
N. IBADOV* \\ Warsaw University of Technology, The Faculty of Civil Engineering, Warsaw, Poland
}

\begin{abstract}
The complexity of construction projects increases the likelihood of hazards affecting their successful implementation. There are many risk factors that lead to the failure of the project. These factors should be identified and ordered both because of their degree of importance (significance) and level (volume) of a given factors. This is very important in order to determine their effect on the construction project. Typically, the threats for the construction project include the extension of the project duration, the increase of the project cost and/or the reduce of the quality of the works. This article aims (1) to identify risk factors that may affect the construction project in Poland in the above-mentioned aspects and (2) to prioritize the significance of those risk factors. Due to the uniqueness of individual construction projects, the potential hazards and their effects are usually characterized by different levels of uncertainty. Unfortunately, it is often a non-statistical uncertainty. For this reason, the degree of significance of risk factors is described and modelled using linguistic variables and elements of the theory of fuzzy sets. This method allows to evaluate the risk of construction projects prior to their implementation.
\end{abstract}

DOI: 10.12693/APhysPolA.130.107

PACS/topics: 07.05.Mh, 87.52.Px

\section{Introduction}

There are many factors influencing the parameters of construction projects realization that give rise to the risk of failure of the project. The survey shows that "2015 Global Construction Project Owner's Survey", more than half of the owners of construction projects came in contact with at least one problematic project despite the belief that they apply the right tools to plan and control their projects [1]. This means that there is a current issue of picking the factors that cause failure in achieving the construction project goals. These factors should be identified and ordered both because of their degree of importance (significance) and level (volume) of a given factor. It is especially difficult because of the specific characteristics of the construction projects implementation process. This specificity lies in the fact that the conditions of individual construction projects are unique which makes it really determine the significance (importance) of risk factors and their level of influence (threat) is carried out under conditions of uncertainty. Unfortunately, it is often a non-statistical uncertainty. As a result, in this article, the author proposes to describe and model the importance level (significance) of factors affecting the cost and time of a construction project using linguistic variables and elements of fuzzy set theory.

\section{Determination and prioritization of risk factors influencing construction project}

Several of the literature sources contain systematized lists of identified circumstances or events, the occurrence of which is a source of deviations of actual project performance (including duration and cost of implementation) from the expected state, defined by the planner. Such circumstances or events are referred to as risk factors, the occurrence of which may threaten the achievement of the project objectives, see for example [2-5].

In this article, factors affecting the duration and work costs are chosen on the basis of analysed literature, taking into account the specifics of the Polish market.

The questionnaire survey was conducted among clients, designers, general contractors, subcontractors and suppliers of building materials from the majority of polish provinces. Data was collected from 133 questionnaires, which has been analyzed to determine the degree of significance (importance) of risk factors taking into account their impact on the execution parameters of construction project. In this paper, the author present only the part of the survey results concerning the influence of chosen factors on the duration and on the cost of the construction project execution. In this regard, each respondent was asked to assess the degree of significance of each factor with one of the following verbal marks: not important (NI), slightly important (SI), moderately important (MI), essentially important (EI), and critically important (CI).

Table I shows the responses in relation to individual risk factors.

In the paper, to describe and formalize the general degree of significance (relative importance) of factors, the elements of the fuzzy sets theory were used. Basic concepts of fuzzy set theory, useful in solving the issue taken, are presented below. 
Selected risk factors and responses.

\begin{tabular}{|c|c|c|c|c|c|}
\hline \multirow[b]{2}{*}{$\begin{array}{l}\text { Risk factors affecting the time } \\
\text { of construction project implementation }\end{array}$} & \multicolumn{5}{|c|}{ Respondents' answers: } \\
\hline & $\begin{array}{c}\text { Not } \\
\text { important } \\
(\mathrm{NI})\end{array}$ & $\begin{array}{c}\text { Slightly } \\
\text { important } \\
\text { (SI) }\end{array}$ & $\begin{array}{c}\text { Moderately } \\
\text { important } \\
(\mathrm{MI})\end{array}$ & $\begin{array}{c}\text { Essentially } \\
\text { important } \\
\text { (EI) }\end{array}$ & $\begin{array}{l}\text { Critically } \\
\text { important } \\
\text { (CI) }\end{array}$ \\
\hline the tight schedule of the project & \begin{tabular}{l|l}
0 \\
\end{tabular} & 3 & 20 & 28 & 82 \\
\hline $\begin{array}{c}\text { changes of material and structural solutions } \\
\text { in project documentation }\end{array}$ & 0 & 9 & 41 & 46 & 37 \\
\hline $\begin{array}{l}\text { excessive complexity of the procedures associated } \\
\text { with obtaining administrative decisions }\end{array}$ & 0 & 12 & 53 & 37 & 31 \\
\hline changes in functional requirements, introduced by the client & 9 & 23 & 45 & 28 & 28 \\
\hline $\begin{array}{l}\text { incomplete project documentation, absence } \\
\text { of the required decisions or permits }\end{array}$ & 2 & 10 & 38 & 47 & 36 \\
\hline incorrect estimation of the scope of works & 6 & 20 & 34 & 39 & 34 \\
\hline incorrect estimation of project timetable & 0 & 0 & 30 & 67 & 36 \\
\hline $\begin{array}{l}\text { excessive length of procedures } \\
\text { for obtaining administrative decisions }\end{array}$ & 0 & 4 & 24 & 66 & 39 \\
\hline $\begin{array}{l}\text { too high expectations regarding } \\
\text { the progress or the quality of the works }\end{array}$ & 22 & 62 & 30 & 19 & 0 \\
\hline changes in the scope of work & 0 & 3 & 21 & 65 & 44 \\
\hline \multirow[b]{2}{*}{$\begin{array}{l}\text { Risk factors affecting the cost } \\
\text { of construction project implementation }\end{array}$} & \multicolumn{5}{|c|}{ Respondents' answers: } \\
\hline & $\begin{array}{c}\text { Not } \\
\text { important } \\
(\mathrm{NI})\end{array}$ & $\begin{array}{c}\text { Slightly } \\
\text { important } \\
\text { (SI) }\end{array}$ & $\begin{array}{c}\text { Moderately } \\
\text { important } \\
(\mathrm{MI})\end{array}$ & $\begin{array}{c}\text { Essentially } \\
\text { important } \\
\text { (EI) }\end{array}$ & $\begin{array}{l}\text { Critically } \\
\text { important } \\
(\mathrm{CI})\end{array}$ \\
\hline the tight schedule of the project & \begin{tabular}{l|l}
5 \\
\end{tabular} & 8 & 48 & 53 & 19 \\
\hline $\begin{array}{c}\text { changes of material and structural solutions } \\
\text { in project documentation }\end{array}$ & 9 & 11 & 52 & 44 & 17 \\
\hline changes in functional requirements, introduced by the client & 22 & 32 & 49 & 26 & 4 \\
\hline incorrect estimation of the scope of works & 4 & 41 & 49 & 19 & 20 \\
\hline litigation between the participants of the project & 0 & 59 & 43 & 20 & 11 \\
\hline increase of prices of construction materials & 57 & 37 & 16 & 14 & 9 \\
\hline $\begin{array}{c}\text { excessive complexity of the procedures associated } \\
\text { with obtaining administrative decisions }\end{array}$ & 12 & 39 & 36 & 20 & 26 \\
\hline $\begin{array}{l}\text { incomplete project documentation, absence } \\
\text { of the required decisions or permits }\end{array}$ & 17 & 21 & 43 & 28 & 24 \\
\hline incorrect estimation of project timetable & 13 & 20 & 60 & 27 & 13 \\
\hline
\end{tabular}

\section{Basic concepts of the theory of fuzzy sets useful in solving the issue taken}

The fuzzy set theory was described in the work of Zadeh [6]. Unlike as in the classical set theory, in the fuzzy set theory it is possible for an element belonging to a set $A_{i}$ to have a degree of membership. That degree is called grade of membership, and is described by a membership function $\mu_{A_{i}}: X \rightarrow[0,1]$. If $\mu_{A_{i}}(x)=1$, an element $x$ is fully included in a set $A_{i}$, and if $\mu_{A_{i}}(x)=0$, an element $x$ is not included in a set $A_{i}$. However, there is a considerable number of elements $x$ which satisfy the condition of belonging to $A_{i}$ only to some extent. For example, we can say that if $\mu_{A_{i}}(x)>0.5$, then an element x seems rather to belong to $A_{i}$, while those elements, for which $\mu_{A_{i}}(x)<0.5$, seem rather to not satisfy the condition of belonging to $A_{i}$.
A fuzzy number is a fuzzy subset of the real line whose highest membership values are clustered around a given real number called the mean value and the membership function is monotonic on both sides of this mean value. Let $A=\left\{\left(x, \mu_{A}(x)\right): x \in X\right\}$ and $B=\left\{\left(y, \mu_{B}(y)\right)\right.$ : $y \in Y\}$ be fuzzy numbers. Basic arithmetic operations on these numbers as addition (+), substraction (-), multiplication $(\cdot)$ and division $(/)$ are as follows [6]:

$$
\mu_{A * B}(z)=\sup _{z=x * y}\left(\min \left(\mu_{A}(x), \mu_{B}(y)\right)\right), \forall x, y, z \in R,(1)
$$

where symbol $(*)$ means respectively $(+),(-),(\cdot)$ or $(/)$ if $y \neq 0$.

One of the important elements of the fuzzy set theory is a linguistic variable which adopts natural language expressions as its value. Despite complex mathematical formalism, intuitive sense of linguistic variables is simple. 
In our case, for example, the linguistic variable called the degree of significance can adopt as its value fuzzy sets that represent the features: not important, slightly important, etc.

In many cases we can encounter the issue of transforming a fuzzy value into precisely defined real number. This procedure is called defuzzification. One of these methods is the center of gravity method, which assigns a real number to membership function. The real (crisp) number $y_{\mathrm{c}}$ determines coordinate of the center of gravity of the area under the graph of a function:

$$
y_{\mathrm{c}}=\frac{\int y \mu(y) \mathrm{d} y}{\int \mu(y) \mathrm{d} y},
$$

where $y_{\mathrm{c}}$ - a real (crisp) number, $y$ - the value of the output variable $\mu(y)$ - the membership function of the output variable.

\section{Modeling the degree of significance of risk factors in the notation of fuzzy sets}

A number of methods and models of construction of linguistic variables membership functions have been proposed, refer for example to $[7,8]$. This includes also the adoption of an appropriate measurement scale. Without going into much detail, for the construction of the appropriate membership function in our case, one should answer the question: "To what extent does the risk factor $x$ belong to fuzzy set A?" or should state that "risk factor $x$ is more $A$ than risk factor $y$ ". This will allow us to construct the membership function of fuzzy set, like in [9]. Basing on ranking of factor degrees of significance obtained during survey, and fuzzy set definition, we are able to determine the membership functions of individual factors on a scale [0,1]. Figure 1 shows membership functions of individual fuzzy sets. With regard to the values shown in Fig. 1, one can describe the analytical notation of membership functions for the linguistic variables used to assess the degree of significance of each factor with verbal marks: not important (NI), slightly important (SI), moderately important (MI), essentially important (EI), and critically important (CI).

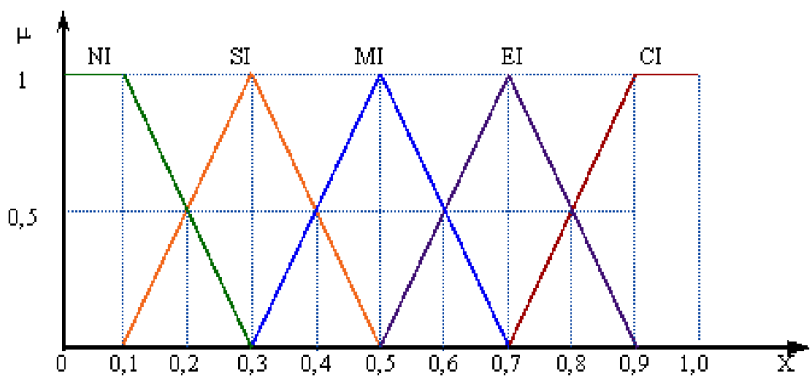

Fig. 1. The membership functions of the degree of significance of a given risk factor.

For example, the analytical notation of membership function "slightly important" $\mu_{S I}$ is given by the formula

$$
\mu_{S I}= \begin{cases}0 & \text { for } x \leq 0.1 \\ \frac{x-0.1}{0.3-0.1} & \text { for } 0.1 \leq x \leq 0.3 \\ \frac{0.5-x}{0.5-0.3} & \text { for } 0.3 \leq x \leq 0.5 \\ 0 & \text { for } x \geq 0.5\end{cases}
$$

Basing on the collected data presented in Table I, the general degree of significance (importance) for each factor can be determined according to formula (4):

$$
W_{f}=\sum w_{i}\left(\frac{n_{i}}{N}\right),
$$

where $W_{f}$ - the design value of the significance for a given factor, included in an interval $[0.0 ; 1.0], w_{i}$ - the coefficient of validity for the $i$-th linguistic variable, determined as the maximum value within the range $[0.0 ; 1.0]$, which corresponds to the maximum value of the membership function of this variable (for example, for the linguistic variable "slightly important", $w_{i}=0.3$, see Fig. 1 ), $n_{i}$ - the number of votes for the $i$-th linguistic variable, $N$ - the total number of votes (in our case, $N=133$ ).

The results are given in Table II (next page).

\section{An example of a construction project risk assessment using the results of survey}

For simplicity, we assume only three chosen risk factors affecting the time and the cost of the construction project (see Table III). Assume that in a given project, the scheduler determines the measurement scale of the degree of occurrence of a given risk factor in the form of the following fuzzy numbers: $\quad$ Low $=(1 / 0.0+1 / 0.2+0 / 0.5)$; Medium $=(0 / 0.2+1 / 0.5+0 / 0.8)$;

High $=(0 / 0.5+1 / 0.8+1 / 1.0)$. Figure 2 shows a graph of the respective linguistic variables. Fuzzy numbers describing the significance of the risk factors are also determined on the basis of Fig. 1, as given in Table III.

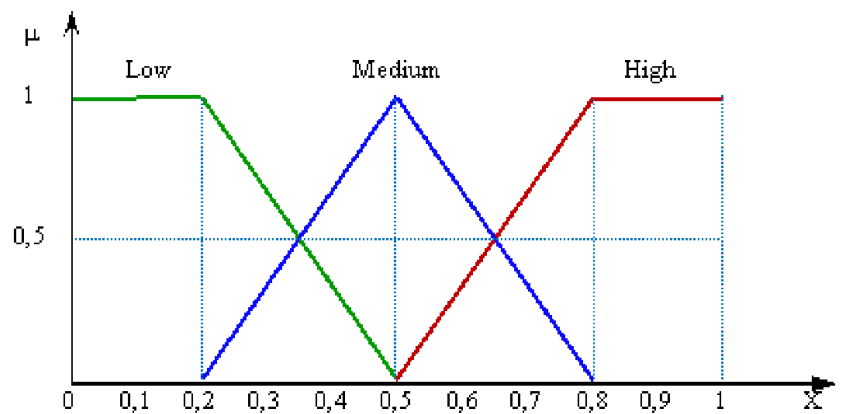

Fig. 2. The membership functions of the degree of occurrence of a given risk factor.

The next step is to multiply the fuzzy number modeling the degree of significance of a given risk factor (i.e., risk impact) by the fuzzy number modeling the degree of occurrence of this factor in a given project (i.e, risk likelihood). Using formula (1), we get the fuzzy number describing the risk severity - the threat for the construction project, caused by a given risk factor (see Table III). 
TABLE II

The significance of risk factors based on respondents' answers.

\begin{tabular}{|c|c|c|}
\hline \multirow[t]{2}{*}{ Risk factors } & \multicolumn{2}{|c|}{$\begin{array}{l}\text { The degree of significance of the } \\
\text { influence on the construction project: }\end{array}$} \\
\hline & Duration & Cost \\
\hline the tight schedule of the project & EI & EI \\
\hline changes of material and structural solutions in project documentation & EI & MI \\
\hline $\begin{array}{c}\text { excessive complexity of the procedures associated } \\
\text { with obtaining administrative decisions }\end{array}$ & EI & MI \\
\hline changes in functional requirements, introduced by the client & MI & MI \\
\hline $\begin{array}{c}\text { incomplete project documentation, absence } \\
\text { of the required decisions or permits }\end{array}$ & EI & MI \\
\hline incorrect estimation of the scope of works & EI & MI \\
\hline incorrect estimation of project timetable & EI & MI \\
\hline $\begin{array}{c}\text { excessive length of procedures } \\
\text { for obtaining administrative decisions }\end{array}$ & EI & - \\
\hline $\begin{array}{l}\text { too high expectations regarding the progress } \\
\text { or the quality of the works }\end{array}$ & SI & - \\
\hline changes in the scope of work & EI & - \\
\hline litigation between the participants of the project & - & MI \\
\hline increase of prices of construction materials & - & SI \\
\hline
\end{tabular}

TABLE III

The evaluation of the threat for the construction project, caused by a given risk factor.

\begin{tabular}{|c|c|c|c|c|}
\hline Risk factors & $\begin{array}{l}\text { The degree } \\
\text { of occurrence }\end{array}$ & $\begin{array}{c}\text { The degree } \\
\text { of significance }\end{array}$ & $\begin{array}{l}\text { The product } \\
\text { of fuzzy numbers }\end{array}$ & $\begin{array}{l}\text { Defuzzi- } \\
\text { fication }\end{array}$ \\
\hline \multicolumn{5}{|c|}{ Risk factors, influencing the project duration } \\
\hline $\begin{array}{c}\text { the tight schedule } \\
\text { of the project }\end{array}$ & $\begin{array}{c}\text { high } \\
(0 / 0.5+1 / 0.8+1 / 1.0)\end{array}$ & $\begin{array}{l}\text { essentially important } \\
(0 / 0.5+1 / 0.7+0 / 0.9)\end{array}$ & $\begin{array}{c}(0 / 0.5+1 / 0.56 \\
+1 / 0.7+0 / 0.72)\end{array}$ & 0.62 \\
\hline $\begin{array}{l}\text { incorrect estimation } \\
\text { of the scope of works }\end{array}$ & $\begin{array}{c}\text { medium } \\
(0 / 0.2+1 / 0.5+0 / 0.8)\end{array}$ & $\begin{array}{l}\text { essentially important } \\
(0 / 0.5+1 / 0.7+0 / 0.9)\end{array}$ & $\begin{array}{c}(0 / 0.25+1 / 0.35 \\
+0 / 0.40)\end{array}$ & 0.334 \\
\hline $\begin{array}{l}\text { incorrect estimation } \\
\text { of project timetable }\end{array}$ & $\begin{array}{c}\text { low } \\
(1 / 0.0+1 / 0.2+0 / 0.5)\end{array}$ & $\begin{array}{c}\text { essentially important } \\
0 / 0.5+1 / 0.7+0 / 0.9)\end{array}$ & $\begin{array}{c}(1 / 0+0 / 0.1+1 / 0.14 \\
+0 / 0.18)\end{array}$ & 0.073 \\
\hline \multicolumn{5}{|c|}{ Risk factors. influencing the project cost } \\
\hline $\begin{array}{c}\text { the tight schedule } \\
\text { of the project }\end{array}$ & $\begin{array}{c}\text { high } \\
(0 / 0.5+1 / 0.8+1 / 1.0)\end{array}$ & $\begin{array}{l}\text { essentially important } \\
(0 / 0.5+1 / 0.7+0 / 0.9)\end{array}$ & $\begin{array}{c}(0 / 0.5+1 / 0.56 \\
+1 / 0.7+0 / 0.72)\end{array}$ & 0.62 \\
\hline $\begin{array}{l}\text { incorrect estimation } \\
\text { of the scope of works }\end{array}$ & $\begin{array}{c}\text { medium } \\
(0 / 0.2+1 / 0.5+0 / 0.8)\end{array}$ & $\begin{array}{c}\text { moderately important } \\
(0 / 0.3+1 / 0.5+0 / 0.7)\end{array}$ & $\begin{array}{c}(0 / 0.24+1 / 0.25 \\
+0 / 0.35)\end{array}$ & 0.28 \\
\hline $\begin{array}{l}\text { incorrect estimation } \\
\text { of project timetable }\end{array}$ & $\begin{array}{c}\text { low } \\
(1 / 0.0+1 / 0.2+0 / 0.5)\end{array}$ & $\begin{array}{c}\text { moderately important } \\
(0 / 0.3+1 / 0.5+0 / 0.7)\end{array}$ & $\begin{array}{c}(1 / 0+0 / 0.06+1 / 0.1 \\
+0 / 0.14)\end{array}$ & 0.06 \\
\hline
\end{tabular}

In order to estimate the level of each type of risk, we determine the real number for each risk factor with the use of defuzzification procedure given by formula (2). At this stage, one is able to determine which factor is associated with the highest (or the lowest) risk level and take (or do not take) this into account during project planning.

Upon the results given in Table III, one can state that the arithmetic mean values of the defuzzified numbers describing the threats for the duration and for the cost of a construction project, are respectively 0.324 and 0.320 . On the basis of these values, using the measurement scale similar to given in Fig. 2, we can evaluate the threat for the duration of the project by the fuzzy set $(0.473 /$ Low; 0.527 /Medium), and the threat for the cost of the project by the fuzzy set $(0.6 /$ Low; $0.4 /$ Medium).

\section{Conclusion}

The survey results present importance (significance) of each factor influencing construction projects. Experts (respondents) opinions were gathered and they are different because of their experience, past projects and range 
of investments. Procedure suggested in this paper allows for calculation of factors' general importance. This way it is easy to qualify each factor to fuzzified importance scale, which are described by relevant membership functions. Due to the procedure set of factors with relevant importance can be created.

The suggested procedure allows manager for selection of the highest levels of threats and common level of threat for analyzed parameters of the project. Use of fuzzy sets theory while prioritizing, describing and modelling of factors allows for better management of the project. It also helps to establish influence level of factors for relevant project parameters.

\section{References}

[1] Global Construction Survey 2015, Climbing the curve, KPMG International.

[2] D. Baloi, A.D. Price, Int. J. Project Manag. 21, 261 (2003).
[3] V. Carr, J.H. Tah, Adv. Eng. Software 32, 847 (2001).

[4] J. Tah, V. Carr, Construct. Managem. Econ. 18, 491 (2000).

[5] P. Zou, G. Zhang, J. Wang, Int. J. Project Manag. 25, 601 (2007).

[6] L.A. Zadeh, Inform. Control 8, 338 (1965).

[7] T. Bilgiç, I.B. Türkșen, in: Fundamental of Fuzzy Sets, The Handbook of Fuzzy Sets, Eds. D. Dubois, H. Prade, Vol. 7, Kluwer, Dordrecht 2000

[8] T. Marchant, Fuzzy Sets Syst. 148, 157 (2004).

[9] N. Ibadov, J. Kulejewski, M. Krzemiński, AIP Conf. Proc. 1558, 1298 (2013). 